\title{
Permeation Properties of Polymer/Clay Nanocomposites
}

\author{
A. Kalendova ${ }^{\text {ab }}$, D. Merinska ${ }^{\text {ab }}$ and J. F. Gerard ${ }^{\mathrm{c}}$ \\ ${ }^{a}$ Centre of Polymer Systems, nam. T.G.Masaryka 5555, 76001 Zlin, Czech Republic, kalendova@ft.utb.cz \\ ${ }^{b}$ Department of Polymer Enginering, Faculty of Technology, Tomas Bata University in Zlin, Nam. T. G. Masaryka \\ 275, 76272 Zlin, Czech Republic \\ ${ }^{c}$ Laboratoire des Matériaux Macromoléculaires IMP INSA de Lyon, Bât Jules Verne, 20 Avenue A. Einstein, \\ 69621 Villeurbanne Cedex - France
}

\begin{abstract}
The important characteristics of polymer/clay nanocomposites are stability, barrier properties and in the case of polyvinyl chloride also plasticizer migration into other materials. Therefore, the permeation properties of polymer/clay nanocomposites are discussed in this paper. The attention was focused to the polyethylene (PE) and polyvinyl chloride (PVC). Natural type of montmorillonite $\mathrm{MMTNa}^{+}$and modified types of montmorillonite from Southern Clay Products were used as the inorganic phase. As the compounding machine, one screw Buss KO-kneader was employed. The principal aim is to fully exfoliate the clay into polymer matrix and enhanced the permeation properties. Prepared samples were tested for $\mathrm{O}_{2}$ and $\mathrm{CO}_{2}$ permeability. Polymer/clay nanocomposite structure was determined on the base of X-ray diffraction and electron microscopy (TEM).
\end{abstract}

Keywords: Polymer, clay, nanocomposite, permeation.

PACS: : Organic-inorganic hybrid nanostructures, 81.07.Pr

\section{INTRODUCTION}

In worldwide commercial importance, polyethylene (PE) is the first and polyvinyl chloride (PVC) is the third most widely produced plastic. ${ }^{[1]}$

Polyethylene (PE) was first synthesized in 1898 by the chemist Hans von Pechmann. The first industrially practical polyethylene synthesis was discovered by Eric Fawcett and Reginald Gibson at the Imperial Chemical Industries (ICI) in 1933. The first industrial production of LDPE was starting in 1939. Because polyethylene was found to have very low-loss properties at very high frequency radio waves, polyethylene was applying for insulation for UHF and SHF coaxial cables of radar sets. In 1944, Bakelite Corporation and Du Pont went into commercial production under licensing agreements with (ICI) ${ }^{[2]}$ Polyethylene is cheap, flexible, durable, and chemically resistant.

Polyvinyl Chloride, PVC, was recognized and characterized more than 100 years ago; it had not become a material of more than academic curiosity until the 1920s and 1930s, though. It became commercially significant in Germany prior to World War II, and it developed very rapidly during the war and in the immediate postwar period in the United States. ${ }^{[3]}$ This material can offer many good properties, such as low flammability, high chemical resistance, low cost, and formulating versatility. ${ }^{[4]}$ On the other hand, PVC mixtures disadvantage is migration and toxicity of some additives used in PVC, which may have a negative impact on the environment and human health. For all that, PVC production is expected to exceed 40 million tons by $2016 .^{[5]}$

Nanocomposites differ from traditional plastic composites in that they provide enhancement properties with minimal impact on article weight and they do so without processing penalties. Lastly, in packaging nanocomposites deliver with good clarity, a combination not possible using traditional composite approaches.

This paper follows up our research of polymer/clay nanocomposite. In this part, the permeation properties of polyethylene and polyvinyl chloride nanocomposites are studied.

(C) 2012 American Institute of Physics 978-0-7354-1061-9/\$30.00 


\section{EXPETIMENTAL}

Polyethylene DOWLEX 2035 supplied by Dow Chemical was used as one of the testing polymer matrix. Other one, the suspension type of PVC (Neralit 652, $\mathrm{K}=65$ ), was supplied by Spolana Neratovice. Dioctylphthalate (DOP), dioctyladipate (DOA) were used as low molecular weight PVC plasticizers, respectively. Natural type of montmorillonite MMTNa+ and modified types of montmorillonite (30B, 25A, 93A) from Southern Clay Products were used as the inorganic phase. Details are possible to see on the websites of named company.

Polymers with the fillers (mass fraction of 5 or $10 \%$ ) were compounded in Buss KO-kneader MKS 30 single screw extruder. Compounding of PE/clay was carried out at $110-190{ }^{\circ} \mathrm{C}, 50 \mathrm{rpm}$. Futher compounding of PVC/clay was carried out at $130-160^{\circ} \mathrm{C}$ using a screw speed $50 \mathrm{rpm}$. Nanocomposites extrudates were then pelletized. Samples for testing, $50 \mu \mathrm{m}$ and $100 \mu \mathrm{m}$ film, were prepared on laboratory twin.

Permeability for oxygen and carbon dioxide was measured in compliance with CSN 640115 at temperature $25^{\circ} \mathrm{C}$ and gas apparent pressure $0,4-0,6 \mathrm{MPa}$.

The structure was studied using an URD-6 Diffractometer with $\mathrm{CuK} \alpha$ radiation $(\lambda=1.54 \AA)$. The dispersion of the clays in PVC matrix and nanostructures were observed through microscopic investigations. For the transmission electron microscopy (TEM) the specimens were prepared by cutting with an ultramicrotome equipped with a diamond knife.

\section{RESULT AND DISCUSSION}

Polymer/clay nanocomposites have been studied for longer period as materials possible used in packaging industry. Therefore this work has been interested in the permeation properties. Tables 1-2 are presenting the permeability coefficient for oxygen and carbon dioxide. In table 1 are obtained data for PE nanocomposites. As can be seen, all used clays (30B, 25A, 93A) exhibit lower permeability coefficient for both gases in the comparison with unfilled PE matrix. Common improvement is around $40 \%$.

TABLE 1. $\mathrm{O} 2$ and $\mathrm{CO} 2$ Permeability of PE Nanocomposites

\begin{tabular}{lccccc}
\hline \multicolumn{1}{c}{ Composition } & $\begin{array}{c}\text { Thickness } \\
(\mathbf{m m})\end{array}$ & $\begin{array}{c}\text { Permeability } \mathbf{Q}\left(\mathbf{O}_{\mathbf{2}}\right) \\
\left(\mathbf{m}^{2 *} \mathbf{P a}^{-1 *} \mathbf{s}^{-1}\right) * \mathbf{1 0}^{-\mathbf{1 7}}\end{array}$ & $\begin{array}{c}\text { Permeability } \mathbf{Q}\left(\mathbf{C O}_{2}\right) \\
\left(\mathbf{m}^{2} * \mathbf{P a}^{-1 *} \mathbf{s}^{-1}\right) * \mathbf{1 0}^{-\mathbf{1 7}}\end{array}$ & $\mathbf{Q}\left(\mathbf{O}_{2}\right)$ & $\mathbf{Q}(\mathbf{C O})$ \\
\hline PE & 0.05 & 2,97 & 9,39 & 0 & 0 \\
PE/MMT30B 5\% & 0.05 & 1,61 & 3,13 & 46 & 67 \\
PE/MMT25A 5\% & 0.05 & 1,82 & 5,68 & 39 & 40 \\
PE/MMT93A 5\% & 0.05 & 1,25 & 6,32 & 58 & 33 \\
\hline
\end{tabular}

TABLE 2. $\mathrm{O}_{2}$ and $\mathrm{CO} 2$ Permeability of PVC Nanocomposites

\begin{tabular}{|c|c|c|c|c|c|}
\hline Composition & $\begin{array}{c}\text { Thickness } \\
(\mathrm{mm})\end{array}$ & $\begin{array}{l}\text { Permeability } \mathbf{Q}_{(\mathrm{O} 2)} \\
\left(\mathrm{m}^{2 *} \mathbf{P a}^{-1 *} \mathrm{~s}^{-1}\right) * \mathbf{1 0}^{-17}\end{array}$ & $\begin{array}{l}\left.\text { Permeability } Q_{(\mathrm{CO})}\right) \\
\left(\mathrm{m}^{2} * \mathrm{~Pa}^{-1 *} \mathbf{s}^{-1}\right) * \mathbf{1 0}^{-17}\end{array}$ & $\begin{array}{l}Q_{(02)} \\
(\%)\end{array}$ & $\begin{array}{c}Q_{(\mathrm{CO} 2)} \\
(\%)\end{array}$ \\
\hline$\overline{\mathrm{PVC} / \mathrm{DOP}}$ & 0.1 & 1.222 & 5.441 & 0 & 0 \\
\hline PVC/DOP+MMT30B 5\% & 0.1 & 0.896 & 3.909 & 27 & 28 \\
\hline PVC/DOP+MMT30B 10\% & 0.1 & 0.704 & 2.979 & 42 & 45 \\
\hline $\mathrm{PVC} / \mathrm{DOP}+\mathrm{MMTNa}^{+} 5 \%$ & 0.1 & 1.378 & 6.730 & -13 & -24 \\
\hline $\mathrm{PVC} / \mathrm{DOP}+\mathrm{MMTNa}^{+} 10 \%$ & 0.1 & 1.401 & 7.342 & -15 & -35 \\
\hline $\mathrm{PVC} / \mathrm{DOA}$ & 0.1 & 2.104 & 10.340 & 0 & 0 \\
\hline $\mathrm{PVC} / \mathrm{DOA}+\mathrm{MMT} 30 \mathrm{~B}$ 5\% & 0.1 & 1.035 & 5.605 & 51 & 46 \\
\hline PVC/DOA+MMT30B 10\% & 0.1 & 0.731 & 3.671 & 65 & 64 \\
\hline $\mathrm{PVC} / \mathrm{DOA}+\mathrm{MMTNa}^{+} 5 \%$ & 0.1 & 1.659 & 7.638 & 21 & 26 \\
\hline $\mathrm{PVC} / \mathrm{DOA}+\mathrm{MMTNa}^{+} 10 \%$ & 0.1 & 1.666 & 7.422 & 21 & 28 \\
\hline
\end{tabular}

In the table 2 the $\mathrm{O}_{2}$ and $\mathrm{CO}_{2}$ permeabilities for $\mathrm{PVC} /$ clay nanocomposites are presented. Improvement around $40 \%$ was observed for PVC mixtures MMT30B+DOP and MMT30B+DOA. The exfoliation was very successful in this case as results from TEM analysis. TEM pictures are presented in Figure 1A, B. In this place it was noted decreasing of permeability for oxygen by $21 \%$ for PVC/DOA+MMTNa ${ }^{+}$in comparison with pure PVC/DOA. Similar results were obtained for $\mathrm{CO}_{2}$ permeability. The last named sample was indicated lower degree of exfoliation (Figure 1C). Samples PVC/DOP+MMTNa $+5 \%$ and $10 \%$ of loading show increase of permeability between $10-$ $40 \%$. Also these samples indicated the low degree of exfoliation. 

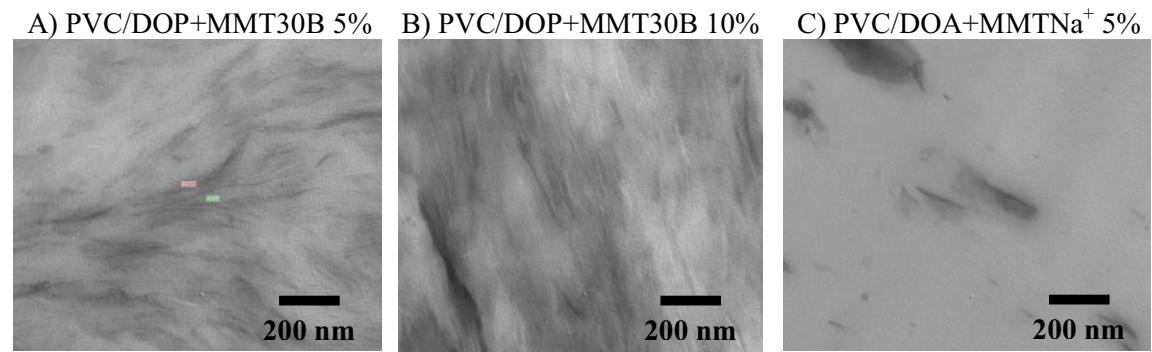

FIGURE 1. TEM Pictures of PVC Nanocomposites

\section{CONCLUSION}

The permeation properties improvement, observed in nanocomposite technology, is caused strictly by the platy nature of montmorillonite. These plates overlap in the matrix and present a large tortuous path to permeant (i.e. water, $\mathrm{O}_{2}$ and $\mathrm{CO}_{2}$ ) migration. The goal in producing a nanocomposite is to achieve full exfoliation. Falling short of this goal has a strong effect on both the relative permeability and clarity of the films.

We can say that improvement around $30 \%$ by PVC nanocomposites is common. In these properties the degree of exfoliation and plate orientation seems to be the most critical parameter.

\section{ACKNOWLEDGMENTS}

This article was created with support of Operational Programme Research and Development for Innovations cofunded by the European Regional Development Fund (ERDF) and national budget of Czech Republic within the framework of the Centre of Polymer Systems project (reg.number: CZ.1.05/2.1.00/03.0111). Further the project FR-TI4/623 is gratefully acknowledged. Special acknowledgement is dedicated to Petr Mertlik, Fatra s.r.o., who carried out the Buss-KO kneader mixing.

\section{REFERENCES}

1. ACC Resin Statistics Annual Summary 2009 vs. 2008. (2010).

Available from: $<\mathrm{http}: / /$ www.americanchemistry.com/s_acc/sec_policyissues.asp?CID=996\&DID=6872>.

2. B. Reiche, "POLY-The All Star Plastic", Popular mechanics, July 1949, p. 126.

Available from:

$<$ http://books.google.cz/books?id=GtkDAAAAMBAJ\&pg=PA126\&dq=popular+mechanics+July+1932+airplane\&hl=en\&ei

$=$ IoAZTePWB-DRnAe63OjPDg\&sa=X\&oi=book_result\&ct=result\&redir_esc $=\mathrm{y} \# \mathrm{v}=$ onepage\&q $\& \mathrm{f}=$ true $>$

3. I. Leonard Nass, “An overview of the PVC industry” in Encyclopedia of PVC Vol. 1., New York: Marcel Dekker, 1976.

4. Yasemin Turhan, Mehmet Dogan, Mahir Alkan, Ind. Eng. Chem. Res., 49, 1503-1513 (2010).

5. M. Ebner, "Ceresana Research Releases New Comprehensive PVC Market Study" in Newswire Today (2008-11-18). Available from: <http://www.newswiretoday.com/news/42864/> 
Copyright of AIP Conference Proceedings is the property of American Institute of Physics and its content may not be copied or emailed to multiple sites or posted to a listserv without the copyright holder's express written permission. However, users may print, download, or email articles for individual use. 